\title{
Spatial variation of post-dispersal seed removal by rodents in highland microhabitats of Spain and Switzerland
}

\author{
Juan Luis García-Castaño ${ }^{1,3 *}$, Johannes Kollmann ${ }^{2}$ and Pedro Jordano ${ }^{1}$ \\ ${ }^{1}$ Integrative Ecology Group, Estación Biológica de Doñana, CSIC, Avda. María Luisa s/n, Pabellón del Perú, \\ 41013 Sevilla, Spain; ${ }^{2}$ Department of Ecology, Royal Veterinary and Agricultural University, Rolighedsvej 21, \\ 1958 Frederiksberg-Copenhagen, Denmark
}

\begin{abstract}
Few data are available and little is known about spatial variation in post-dispersal seed removal at different levels throughout the geographic range of a plant species. Here, we compare post-dispersal seed removal by rodents within and among sites in two distinct regions, the south-eastern Spanish Mediterranean highlands and the Swiss Jura. Seed removal was assessed experimentally for four fleshyfruited species (Berberis vulgaris, Crataegus monogyna, Rosa spp. and Taxus baccata) in heterogeneous sites with distinct microhabitats. A factorial general linear model (GLM) analysis was used to evaluate the relative influence of speciesspecific seed traits on removal at three spatial levels (microhabitat, site and region). In both highland ecosystems, live trapping revealed that rodents were the main seed removers: Apodemus sylvaticus was observed in both regions, whereas $A$. flavicollis and Clethrionomys glareolus occurred only at the Swiss sites. There was a significant difference in seed removal between regions, and the preferences of the rodents varied among plant species and microhabitats. Variation in rodent presence explained some differences in seed removal between regions and among microhabitats. Finally, the effect of rodent presence on seed removal differs due to both regional and microhabitat effects.
\end{abstract}

Keywords: Apodemus flavicollis, Apodemus sylvaticus, Clethrionomys glareolus, Mediterranean highlands, seed dispersal, seed removal, Swiss Jura

*Correspondence

Fax: + 34954557059

Email: jlgc@us.es

${ }^{3}$ Present address: Departamento de Biología Vegetal y Ecología, Universidad de Sevilla, Apdo-1095, 41080 Sevilla, Spain

\section{Introduction}

Post-dispersal seed removal is a significant process for plant recruitment, during which many propagules are lost, with marked effects for plant demography in many species (Davidson, 1993; Heske et al., 1993; Hulme, 1997, 2002; Wang et al., 2000; Maron and Simms, 2001; but see Alcántara et al., 2000). In the whole distribution range of a plant species, the potential effect of seed losses may depend on the spatial level investigated, and needs to be compared with the spatial patterns in seed dispersal and seedling recruitment (Kollmann, 2000). Numerous studies have revealed significant differences in seed removal when comparing habitats or microhabitats, e.g. increased removal by rodents under patches of bramble (Schreiner et al., 2000), reduced losses in open microhabitats (Hay and Fuller, 1981; Kollmann, 1995; Holl and Lulow, 1997; Hulme, 1997) or higher removal rates along forest edges (Kollmann and Buschor, 2003). However, most studies have considered exclusively a local level, and little information is available about variation in seed removal among comparable habitats for large geographical units, encompassing a species' distribution range (Fedriani et al., 2004). Even rarer are coordinated experiments at different spatial levels, where the relative importance of microhabitats, habitats, landscapes and regions is studied to explain variation in post-dispersal seed removal (Kollmann, 2000). Consistencies of speciesspecific differences in seed removal have been shown for a set of 12 fleshy-fruited species in south-west Germany and southern England, albeit only at one site per country (Kollmann et al., 1998). Consistencies in removal patterns may be a precondition for strong (co)evolutionary interactions between seed removers and plant species, because of the potential wide range of dispersal in fleshy-fruited species by frugivorous animals (Hulme and Benkman, 2002). Plant-seed remover interactions presumably vary strongly throughout a species' range, with potential effects on 
plant-animal coevolution (Thompson, 1999; Benkman et al., 2003; Fedriani et al., 2004).

Here, we compare a detailed investigation of rodent seed removal in highland habitats of south-eastern Spain (García-Castaño, 2001) with a more restricted study in similar habitats in northern Switzerland. The main objective of the present work was to investigate whether or not differences among plant species, sites and microhabitats - in the proportion of seeds lost due to rodent seed removal - are consistent in both regions. As far as we know, this is the first study that compares the relative importance of species, microhabitat, site and region with a coordinated spatial design at three different levels.

The central hypothesis was that post-dispersal seed removal is species-specific, caused by differences in seed traits, including size, nutrient content and toxins, with additional variation due to microhabitat structure; less variation was expected between sites and regions. The spatial differences may be attributable to differences in composition, presence and/or activity of the seed remover guild. This hypothesis leads to the following predictions: (1) the relative importance (i.e. explained variance) of the factors 'plant species' and 'microhabitat' (singly or interacting) should be greater than that of the other spatial levels; (2) microhabitat effects across sites should be independent of regional differences; and (3) variation in seed removal rates should reflect variation in rodent presence at the different spatial levels considered.

\section{Materials and methods}

\section{Study sites}

The Spanish study sites were located in the Sierra de Cazorla, Segura and Las Villas Natural Park (Navahondona-Guadahornillos Reserve, Jaén province, south-eastern Spain). The three study sites were 'Cercado A' and 'Cercado $N^{\prime}$ (in Nava de las Correhuelas, located within c. $0.5 \mathrm{~km}$ of each other), $\mathrm{CA}$ and $\mathrm{CN}$ hereafter, and CAL (Calarilla, c. $3.0 \mathrm{~km}$ away), all within $2^{\circ} 51^{\prime}-2^{\circ} 53^{\prime} \mathrm{W}$ and $37^{\circ} 55^{\prime}-37^{\circ} 57^{\prime} \mathrm{N}$ (1600-1750 $\mathrm{m}$ above sea level). The sites have calcareous bedrock with a mosaic of rock and open soil of 'poldje' type, as often found in karstic landscapes. Vegetation patches cover c. $30 \%$ of the area, and consist of various fleshy-fruited shrubs and small trees; the most abundant tree is Pinus nigra (for more details, see Jordano and Schupp, 2000). The climate is of a Mediterranean highland type (for further details of the study sites, see Valle et al., 1989; Jordano, 1995; García-Castaño, 2001).

In northern Switzerland, two study sites were selected (RE, 'Rütifels' near Remigen, and TH, 'Staffelegg' near Thalheim), which are about $9.0 \mathrm{~km}$ apart in the Swiss Jura mountain range (Swiss Grid Reference: RE, 656.050/264.025; TH, 648.325/254.600; altitude: RE, $590 \mathrm{~m}$; TH, $680 \mathrm{~m}$ ). The sites were chosen in this region because the vegetation and the mosaic of microhabitat types are fairly similar to those of the Spanish sites. Both sites include south- to south-westfacing calcareous cliffs, extensive scree slopes, adjacent shrublands and light forest stands of $c .0 .2 \mathrm{ha}$. The study sites have probably never been covered by forest since the last glaciation (C.A. Burga, personal communication), and have had minimal human interference. The climate is of a central European highland type (for more information about the sites, see Kirchhofer, 1982; Kollmann and Pflugshaupt, 2001, 2005; Pflugshaupt et al., 2002).

\section{Seed removal}

A factorial design was used to investigate differences in the proportion of seeds lost due to post-dispersal seed removers among different plant species, with a focus on variation of removal at three spatial levels: 'region' and 'site' (the latter geographically nested within the former), and 'microhabitat' (common to the different sites and regions considered). This experimental design was not established a priori; in Switzerland, it was intentionally developed for this comparison, whereas in Spain we used summarized data, corresponding to a subset of species common to both regions, from a larger experiment that had a different goal (García-Castaño, 2001). This way of matching both regions allowed us to investigate some key factors explaining variable levels of post-dispersal seed removal.

\section{Study species}

Species-specific differences in seed removal were tested with fleshy-fruited species, because vertebrate frugivores produce distinct spatial patterns of seed dispersal in this group, which then might be modified by rodent seed removers (Kollmann, 2000). We selected four fleshy-fruited woody species (one tree and three tall shrubs) that are common both in the Spanish and Swiss study sites, and differ largely in their attractiveness to rodent seed removers, as shown in previous studies (Kollmann et al., 1998; García-Castaño, 2001). Moreover, the study species are large seeded, have no masting, develop no long-term seed bank, show little vegetative regeneration, and thus are prone to detrimental effects of seed removal (Hulme, 1998). The species used were Berberis vulgaris L. (Berberidaceae), Crataegus monogyna Jacq. (Rosaceae), Rosa spp. (Rosaceae), and Taxus baccata L. (Taxaceae). Within Rosa spp. eight closely related species 
and microspecies, which hybridize in the Spanish sites and show relatively small differences in their seed traits, were pooled. Seed masses of the species were: $13.2 \pm 1.1 \mathrm{mg}$ (B. vulgaris), $99.0 \pm 13.9 \mathrm{mg}$ (C. monogyna), $\quad 14.8 \pm 1.5 \mathrm{mg} \quad$ (Rosa spp.) and $57.3 \pm 5.6 \mathrm{mg}$ ( $T$. baccata) (means $\pm \mathrm{SD}, 10$ samples of 10 seeds each).

Fruit material was collected from 5-10 individuals per species in the Spanish sites. The fleshy tissue of the fruit was removed by hand. Seeds were dried at room temperature and thereafter stored at about $4^{\circ} \mathrm{C}$; for further details see García-Castaño (2001). We use the terms 'seed' and 'fruit' in their functional meaning during consumption and dispersal by frugivorous animals. The same seed material was employed in the Spanish and the Swiss sites to make the studies strictly comparable; differences in seed traits of the study species are minor between the two regions (cf. Herrera, 1987; Kollmann et al., 1998).

\section{Microhabitats}

To evaluate the effect of the microhabitats where seed deposition by frugivores occurs, we selected three microhabitat types for the Spanish sites out of those defined by Jordano and Schupp (2000) and GarcíaCastaño (2001): (1) 'high shrub', individual trees or tall shrubs $(>1 \mathrm{~m})$, belonging to fleshy-fruited species such as C. monogyna, Juniperus phoenicea, Lonicera arborea, Prunus mahaleb, Rosa spp. and T. baccata (nomenclature after Tutin et al., 1968, 1976; Castroviejo et al., 1986, 1990; Muñoz Garmendia and Navarro, 1998); (2) 'non-fleshy-fruited tree', individuals of P. nigra; and (3) 'open' substrate, locations with deep soil or rocks, often covered by herbs, but without tall woody vegetation. In Switzerland, the same microhabitat types were chosen, as judged by substrate and vegetation cover, although the species composition of herbaceous and woody vegetation was slightly different. The high shrub type included mainly Rosa spp., P. mahaleb, Cornus sanguinea and Corylus avellana, while the non-fleshy-fruited tree type included Pinus sylvestris, Fagus sylvatica, Quercus petraea, Ulmus minor and Tilia cordata, among others.

At each site we randomly selected sampling locations of every type of microhabitat; the total number of locations per microhabitat and region ranged from 26 to 32 . Mean distance $( \pm S D)$ of a sampling location (i.e. pair of Petri dishes, see below) to the nearest one was $18.5 \pm 12.3 \mathrm{~m}$ (distance data obtained for the Spanish region). The final layout of experimental stations consisted of 81 sampling points (27, 28 and 26 of microhabitat types 1, 2 and 3, respectively) in Spain, and 96 points (32 of each microhabitat type) in Switzerland.

\section{Experimental set-up}

Seed removal was studied in the field using paired Petri dishes (9.0 cm diameter) placed $1 \mathrm{~m}$ apart at each sampling location. The feeding stations had small holes in the bottom dish for water drainage, and the seeds were additionally protected against rainfall by a second Petri dish that was held inverted about $8.0 \mathrm{~cm}$ above the bottom one by means of three thin bamboo sticks (cf. Kollmann and Buschor, 2003). One feeding station ('open treatment') was accessible to all potential seed removers (rodents, birds, insects, molluscs). In the second station ('closed treatment'), rodents and birds were excluded by a wire mesh $(1.2 \mathrm{~cm}$ mesh size), which also supported the upper dish. The closed treatment was used as a control to assess background seed loss due to factors such as rain, runoff, wind, etc. For further critical comments on the seed dish technique, see Kelrick et al. (1986). The set-up was identical for all sites and similar to those used previously by Abramsky (1983), Willson and Whelan (1990), Hulme (1997) and Kollmann et al. (1998).

\section{Seed removal monitoring}

In each dish, we deposited three seeds. Removal levels were estimated by counting the remaining seeds in each dish; monitoring of the experimental dishes was carried out several times per sampling point in Spain and once in Switzerland. Each sampling location had its own control dish; so, if any seeds disappeared in the control, the replicate location was no longer considered. In Spain, seeds were exposed between late September 1997 and late January 1998; the study in Switzerland was completed in early March 1999. In Spain, we monitored the experimental dishes for a period of $40-47 \mathrm{~d}$, with checking intervals ranging from $2 \mathrm{~d}$ at the beginning (to increase accuracy) up to $22-29 \mathrm{~d}$ at the end of the exposure period. The study species were exposed sequentially in three different runs of the experiment: starting with $B$. vulgaris, then T. baccata, and later the pair C. monogyna-Rosa spp. In Switzerland, we carried out a single monitoring after $3 \mathrm{~d}$ of exposure. The four species were tested in two consecutive runs, first the pair B. vulgaris-T. baccata, and then C. monogyna-Rosa spp. For both regions, every sampling location had one single species tested per run, re-using them in the following run with a different study species.

\section{Rodent trapping}

After the seed monitoring periods, to avoid alterations or interference, we carried out a rodent trapping programme at the same sampling locations used for 
the seed removal experiments. In Spain, every fortnight from late September 1998 to mid January 1999, we operated Sherman live traps at both CA and $\mathrm{CN}$ sites during the night. We set up the traps in half of the experimental points for the first night, and the following night in the other half. Trapping at night seemed sufficient, since the rodents in this study show highest activity at these hours (cf. Jensen, 1993).

The traps were baited with peanut butter spread on a piece of bread and a cotton ball as bedding. Once a mouse was captured, it was released and the trap cleaned to avoid interference with the following potential capture (see Stoddart and Smith, 1986; Gurnell and Little, 1992). This allowed us to estimate the potential rodent pressure, regardless of recaptures of the same individual. In Switzerland, the traps were set immediately after completing the seed removal experiment (early March 1999). The presence of rodents at the seed dishes was inferred from rodent faeces or trapped rodents in the same place, as well as any other visual sign of activity near the experimental set-up.

\section{Statistical analyses}

We considered two possible states for the seeds: present (0) or absent due to rodent seed removal (1); for each sampling location we obtained the proportion for the states 0 or 1 , and we stopped monitoring any experimental replicate for which the control (closed treatment) had lost seeds. The proportion of seeds removed was first divided by the number of nights of exposure and secondly, in Spain, by the number of checks completed per location point, assuming a constant removal rate; this allowed us to obtain both a more representative value of seed removal per location and species in Spain, and to account for any potential bias arising from differences in sampling effort between the two regions. Rodent presence was estimated as the average number of individuals captured per sampling location for each monitoring interval. The proportions of seeds removed, as well as rodent presence, were arcsine-square root transformed prior to analyses.

We fitted a general linear model (GLM) with the site effect introduced as a random blocking factor, and its associated significance was assessed with the 'method of moments'. We considered the site effect nested within region according to the geographical location of the study sites. The microhabitat effect was crossed for all levels of the region, as similar microhabitats were considered in the two regions, and treated as a fixed effect. Thus, we established a comparison between Spain and Switzerland for four common fleshy-fruited species, and in this context, any study area within each country was considered as random, in order to extrapolate to the whole region, whereas extrapolations to other regions or species were not possible under this analysis. The denominator mean squares (MS) used for the $F$ tests was adjusted for the nested design. To compare the relative magnitude of the significant effects on the per-night estimates of seed removal rate, we estimated the corresponding variance components (negative values were treated as if they were zero) and re-scaled them to the global $R^{2}$ of the model (cf. Sokal and Rohlf, 1995).

To evaluate how the presence of rodents could influence the patterns observed, we evaluated the changes in significance of the model fit after incorporating rodent presence as a covariate. For data in Spain, we matched the average date of every seed exposure interval with the rodent presence/absence in the nearest Julian day. We calculated the mean for the specific sampling location and species considered, both for the seed removal rate and the rodent presence values. This assumed similar spatiotemporal patterns in rodent presence, despite interannual fluctuations in total abundance. In Switzerland, we used the rodent trapping data obtained immediately after the removal experiment.

All statistical analyses were performed with the program JMP 5.0.1a (SAS Institute Inc., Cary, North Carolina, USA). Estimates of seed removal rates are expressed as the back-transformed (arcsine-square root) least squares means, obtained under the specified model, as well as its $95 \%$ confidence interval.

\section{Results}

\section{Relative importance of effects influencing seed removal levels}

The whole model of variation in seed removal in both highland regions was significant (MS $=0.22$, $\left.F_{26,313}=4.16, P<0.0001, R^{2}=0.195\right)$. Factors with significant effects included plant species, microhabitat, plant species $\times$ microhabitat interaction and region (for statistical results see Table 1 and Fig. 1). All other effects were not significant, including the interaction terms (except the plant species $x$ microhabitat interaction already pointed out), as well as the site [region] effect (used as a blocking factor).

Removal rates were higher in Spain than in Switzerland, indicating a regional effect; the backtransformed least squares means for the proportion of seeds removed per night of exposure in the Spanish and Swiss sites were $0.073(0.052-0.098)$ and 0.026 (0.016-0.039) (mean and 95\% CI, respectively, Fig. 1). A Tukey-Kramer HSD test $(\alpha=0.05, Q=3.29)$ revealed that seed removal in $T$. baccata was significantly different between the high shrub 
Table 1. Multifactorial analysis of variation in seed removal by rodents at three spatial levels. Results of the general linear model (GLM) fitted for seed removal rates; for more methodological details see the main text (NS, $P>0.05$ )

\begin{tabular}{lcccc}
\hline Effect & MS & df & $F$ & $P$ \\
\hline Plant species & 0.68 & 3 & 12.86 & $<0.0001$ \\
Region & 0.96 & 1 & 14.51 & 0.0336 \\
Site[Region] $]_{\text {random }}$ & 0.07 & 3 & 1.24 & NS \\
Microhabitat & 0.40 & 2 & 7.46 & 0.0007 \\
Plant species $\times$ Region & 0.04 & 3 & 0.70 & NS \\
Plant species $\times$ Microhabitat & 0.16 & 6 & 2.94 & 0.0083 \\
Region $\times$ Microhabitat & 0.03 & 2 & 0.53 & NS \\
Plant species $\times$ Region $\times$ Microhabitat & 0.08 & 6 & 1.43 & NS \\
Error & 0.05 & 313 & & \\
\hline
\end{tabular}

and open microhabitats [the least squares estimates for the back-transformed proportion of seeds removed per night for the high shrub, non-fleshy-fruited tree and open microhabitats were 0.167 (0.110-0.233), $0.088(0.048-0.139)$ and $0.021(0.004-0.051)$, respectively, mean and $95 \% \mathrm{CI}$, whereas no significant differences among microhabitats were found for the other plant species (Fig. 1).

The plant species effect, the microhabitat effect and their interaction accounted for $11.9 \%$ of the variance $(6.5 \%, 2.7 \%$ and $2.8 \%$, respectively), whereas the region effect accounted for only $5.8 \%$.

\section{Differences in rodent presence}

Apodemus sylvaticus L. was the only post-dispersal seed remover in the Spanish sites $(n=42$ rodents trapped out of 139 traps set, associated with the replicate sampling locations analysed here). In Switzerland, three rodent species were recorded in the live traps (82 traps set). Here, Clethrionomys glareolus (Schreber) was most abundant (four of eight rodents), followed by three Apodemus flavicollis L. and one A. sylvaticus L. Fifteen additional locations showed rodent presence, although identification was not possible. Rodent presence varied significantly among sites within regions and among microhabitats, with no significant differences between regions, as well as no significant region $\times$ microhabitat interaction (for the complete model: $\mathrm{MS}=1.79$, $F_{7,243}=4.04, P=0.0003, R^{2}=0.079$; see Table 2 and Fig. 2).

The differences among microhabitats were significant [sum of squares $(\mathrm{SS})=4.30, F_{2,243}=4.85$, $P=0.0086]$, and a Tukey-Kramer HSD test ( $\alpha=0.05, Q=2.36$ ) detected differences between the high shrub and open microhabitats, with a lower rodent presence in the latter. The back-transformed least squares means for the proportion of locations with rodent presence were $0.287(0.157-0.438)$ and $0.054(0.008-0.138)$ for the high shrub and open microhabitats, respectively, and 0.200 (0.094-0.334) for the non-fleshy-fruited tree microhabitat (see Fig. 2).

When rodent presence was included in the overall model, the amount of explained variance increased slightly $\quad\left(\mathrm{MS}=0.20, \quad F_{26,224}=4.05, \quad P<0.0001\right.$,

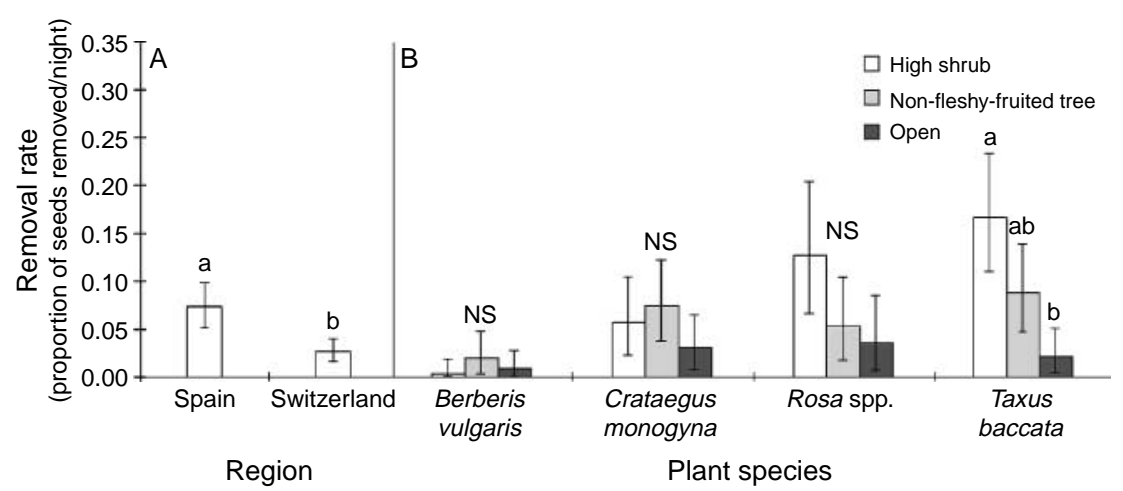

Figure 1. Variation in seed removal rates (A) between regions (proportion of seeds removed per night in Spain and Switzerland); and (B) among microhabitats by plant species (proportion of seeds removed per night in the three studied microhabitats for the four species considered in this work). Values show back-transformed least squares means and $95 \%$ confidence intervals. Different letters are used for significantly different estimates (NS, $P>0.05$ ). 
Table 2. Summary of the general linear model (GLM) fitted for rodent presence at three spatial levels (NS, $P>0.05$ )

\begin{tabular}{lcrcc}
\hline Source & MS & df & $F$ & $P$ \\
\hline Region & $<0.0001$ & 1 & $<0.0001$ & NS \\
Site[Region] & 2.34 & 2 & 5.27 & 0.0058 \\
Microhabitat & 2.15 & 2 & 4.85 & 0.0086 \\
Region $\times$ Microhabitat & 0.71 & 2 & 1.61 & NS \\
Error & 0.44 & 243 & & \\
\hline
\end{tabular}

$R^{2}=0.241 ;$ Table 3). On the one hand, the plant species effect was still significant, and the rank order of decreasing removal rates for the study species was: T. baccata $>$ Rosa spp. $>$ C. monogyna $>$ B. vulgaris. The back-transformed least squares means and $95 \% \mathrm{CI}$ for the proportion of seeds removed per night of exposure and overall average rodent presence were 0.094 (0.065-0.129), 0.086 (0.048-0.133), 0.042 (0.022$0.068)$ and $0.010(0.002-0.024)$, respectively. A TukeyKramer HSD test $(\alpha=0.05, Q=2.59)$ detected significant differences between T. baccata, C. monogyna and $B$. vulgaris, with Rosa spp. being significantly different to $B$. vulgaris, but not to $T$. baccata or C. monogyna. On the other hand, previously mentioned microhabitat-related effects were no longer significant, i.e. the microhabitat and plant species $\times$ microhabitat interaction (details in Table 3).

However, there was a significant region $x$ microhabitat interaction (without rodents: $\mathrm{MS}=0.03$, $F_{2,313}=0.53, \quad P>0.05$; with rodents: $\mathrm{MS}=0.28$, $\left.F_{2,224}=5.64, P=0.0041\right)$. As there was no significant region $\times$ microhabitat interaction for rodent presence (Table 2), this change in significance was due to a differential intensity of removal behaviour, as a

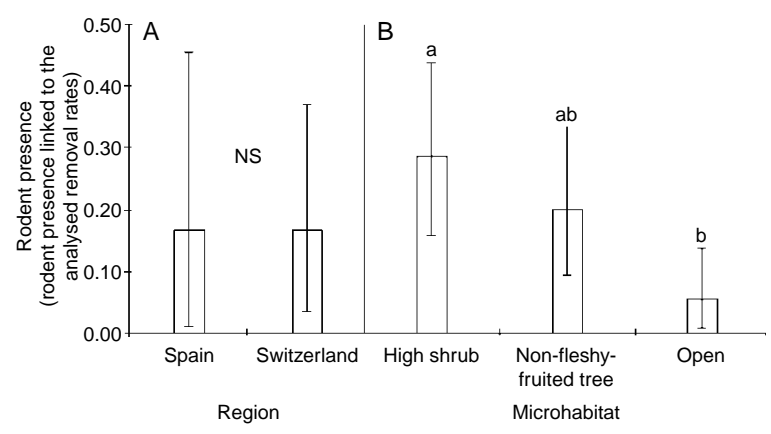

Figure 2. Variation in rodent presence (A) between regions (average rodent presence, for the locations and species considered, in Spain and Switzerland); and (B) among microhabitats (average rodent presence, for the locations and species considered, in the three microhabitats studied). Values show back-transformed least squares means and $95 \%$ confidence intervals. Different letters are used for significantly different estimates (NS, $P>0.05$ ). function of a specific region and microhabitat (Fig. 3). A Tukey-Kramer HSD test $(\alpha=0.05, Q=2.87)$ revealed the following significant differences: (1) intensity of rodent activity in Switzerland was different between the high shrub and open microhabitats [back-transformed least squares means estimates and $95 \%$ CIs for the proportion of seeds removed by night of exposure and overall average rodent presence were $0.064(0.038-0.098), 0.036$ $(0.017-0.062)$ and $0.008(0.001-0.022)$ for the high shrub, non-fleshy-fruited tree and open microhabitats, respectively], whereas in Spain, there were no significant differences among microhabitats; (2) in the open microhabitat, rodents were less active in Switzerland than in Spain [back-transformed least squares means estimates and 95\% CIs for the proportion of seeds removed by night of exposure and overall average rodent presence were 0.008 (0.001-0.022) and $0.089(0.047-0.143)$ for Switzerland and Spain, respectively], whereas no significant differences between regions were found for the other microhabitats.

The plant species effect, again, was most important, accounting for $8.2 \%$ of the variance, whereas the region and the region $\times$ microhabitat interaction accounted for $8.7 \%$ (2.4\% and $6.3 \%$, respectively).

To sum up, the main differences in removal rates were: (1) among microhabitats (only for one species, with higher removal rate in high shrub compared with open microhabitat), and (2) between regions, with consistently higher removal rates in Spain than in Switzerland.

\section{Discussion}

\section{Identity of the seed removers}

Both invertebrates (Cromar et al., 1999) and vertebrates (Gryj and Domínguez, 1996) have been recorded as post-dispersal seed removers (for a review, see Hulme and Benkman, 2002). In our study, only small rodents were observed as removers, with some differences in species composition between the two regions. This seed remover guild is typical for cool-temperate ecosystems (Hulme, 1997; Kollmann et al., 1998), and may include some species able to act as secondary dispersers (Norconk et al., 1998; Hulme and Kollmann, 2005).

Disappeared seeds in the control dishes were associated with rain and wind, and thus excluded from the analyses; ant activity was very low, both in the Spanish and the Swiss sites, and virtually absent during the cold months when the experiments were done (J.L. García-Castaño, personal observations). Our experimental design did not allow us to distinguish between seed removal by rodents 
Table 3. Results of the general linear model (GLM) fitted for seed removal, including rodent presence as covariate (NS, $P>0.05$ )

\begin{tabular}{lcccc}
\hline Effect & MS & df & $F$ & $P$ \\
\hline Plant species & 0.57 & 3 & 11.26 & $<0.0001$ \\
Region & 0.50 & 1 & 23.65 & 0.0075 \\
Site[Region] $]_{\text {random }}$ & 0.02 & 2 & 0.34 & NS \\
Microhabitat & 0.06 & 2 & 1.25 & NS \\
Plant species $\times$ Region & 0.04 & 3 & 0.83 & NS \\
Plant species $\times$ Microhabitat & 0.08 & 6 & 1.51 & NS \\
Region $\times$ Microhabitat & 0.28 & 2 & 5.64 & 0.0041 \\
Plant species $\times$ Region $\times$ Microhabitat & 0.05 & 6 & 1.03 & NS \\
Rodents & 0.72 & 1 & 14.42 & 0.0002 \\
Error & 0.05 & 224 & & \\
\hline
\end{tabular}

and birds, but the effect of the latter is negligible in the study species (Kollmann et al., 1998; J.L. GarcíaCastaño, unpublished data). Potential seed-predatory birds, such as Coccothraustes coccothraustes L. and Carduelis chloris L., are scarce in both regions or, as Emberiza spp., feed mainly in the open microhabitat, where we generally recorded the lowest seed removal rates. Loxia curvirostra L. was abundant in some months, but mainly forages on Pinus nigra cones, acting as a pre-dispersal seed predator (García-Castaño, 2001 for the Spanish sites). Additionally, rodent urine, droppings and seed remnants were often associated with seed losses from the experimental dishes (cf. Kollmann and Buschor, 2003) and, based on previous studies, we estimated that most seeds removed by rodents were actually consumed and thus destroyed (cf. Hulme, 1997). Therefore, rodents were likely to be the main seed predators in this study.

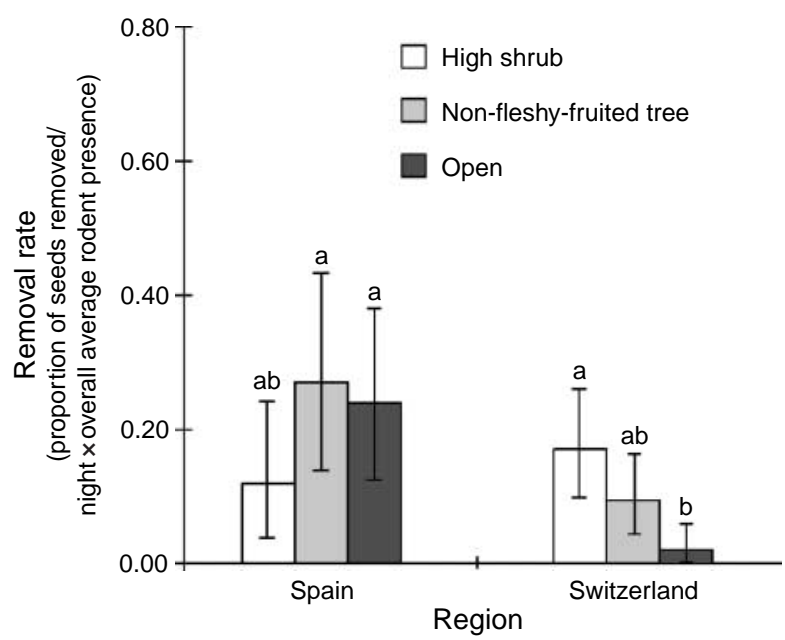

Figure 3. Proportion of seeds removed per night and overall average rodent presence in the three microhabitats studied for the two regions. Values show back-transformed least squares means and 95\% confidence intervals. Different letters are used for significantly different estimates.

\section{Spatial levels explaining variation in seed removal}

Our results showed that species-specific and microhabitat-related effects were more important in determining seed removal rates than differences between regions (11.9\% versus $5.8 \%$ without including differences in rodent presence). For T. baccata, the high shrub microhabitat showed higher seed losses than the open microhabitat; this pattern was evident only for the most preferred species, as shown by the significant plant species $\times$ microhabitat interaction (cf. Myster, 2003). This interaction might have important consequences for the distribution of species diversity at a community level. Differences between regions (i.e. higher removal levels in Spain than in Switzerland) could be related to differences in rodent presence or activity, due to factors such as rodent guild composition, carnivorous predator pressure, availability of other food sources or the moment of exposure (cf. Díaz et al., 1999; Picó and Retana, 2000; Wang et al., 2000).

We detected differences in rodent presence among microhabitats (cf. Díaz et al. 1999). The microhabitat with dense cover, potentially more protective against carnivorous predators, was preferred by rodents, and consequently, might be related to the higher seed losses found, as in other studies in the temperate zone (for a review, see Hulme and Kollmann, 2005).

Finally, when rodent presence was included as a covariate, previously significant microhabitat-related effects vanished, with the region effect as well as the plant species effect remaining significant. In this analysis, T. baccata and Rosa spp. were the most preferred species. The significance of the region $x$ microhabitat interaction, once variation in rodent presence was accounted for, indicated region-specific variation in removal rates per rodent among microhabitats. Specifically, a lower seed removal level relative to rodent presence in the open microhabitat of Switzerland was observed in comparison to the high shrub microhabitat of the same region and the open microhabitat of Spain. This region-related difference may reflect less favourable weather conditions in 
Switzerland for rodent foraging in the open, higher pressure by carnivorous predators, differences in rodent behaviour associated with changes in the background food availability, the moment of exposure or differences in the rodent guild composition. More specifically, differences in diet between Apodemus spp. and Clethrionomys glareolus might be important. As $A$. sylvaticus and A. flavicollis are more granivorous and $C$. glareolus is more of a generalist (cf. Hansson, 1985; Castien and Gosálbez, 1996), seed removal would be less intense where C. glareolus was the only seed consumer, i.e. in the open areas in Switzerland (data not shown). Whatever the case, variations at a microhabitat and regional level in post-dispersal seed removal were explained by differences in rodent behavioural patterns, including both differences in presence and rodent community composition (or intensity of its activity).

Our results suggest that variation in rodent presence or activity resulted in variable and predictable differences in seed removal after primary dispersal. However, temporal changes in rodent abundance might alter this pattern and obscure differences. As our experiment was carried out in a single reproductive season for the plants, it would be interesting to check whether microhabitat-specific differences in rodent pressure on seeds remain consistent among years, presumably encompassing variable ecological settings.

\section{Consequences of variation in seed removal for plant demography}

Several studies, ranging from small to large geographical levels, have documented spatial patterns in seed losses. However, studies at small levels have shown that the Janzen-Connell model is not general (Hyatt et al., 2003), and analyses at large levels have found no significant trend in latitudinal variation of seed losses (Moles and Westoby, 2003). At an intermediate level, Rey et al. (2002) detected a potential effect of seed losses on community biodiversity, depending on altitude. The present study contributes to this debate in the context of regional variation in seed dispersal at this level.

When frugivores disperse fleshy-fruited species over large distances, the probability of seed survival depends mainly on the assortment of plant species and the microhabitat of deposition, and secondarily on region-related effects. Species-specific differences are most important for post-dispersal seed survival, but see Blaney and Kotanen (2001), who found no general difference between native and exotic species, whereas Smith et al. (1989) showed that differences in the seed remover guilds in different sites could translate into differences in removal pressure.

More interesting was the loss in significance of some effects when variation in rodent presence was incorporated. Differences due to microhabitat, as well as the plant species $\times$ microhabitat interaction, disappeared (although the region $\times$ microhabitat interaction became significant). Thus, spatial heterogeneity in the form of microhabitat patchiness imposed constraints on rodent foraging that can translate into variable removal pressures on dispersed seeds, explained by rodent presence and by differences in rodent activity related to spatial variation.

Both post-dispersal survival and secondary dispersal of seeds have important consequences for demography and micro-evolutionary processes (Heske et al., 1993; Hulme, 1998; Thompson, 1999; Hulme and Benkman, 2002; Benkman et al., 2003). By considering multiple influences on post-dispersal seed removal, our study indicated that the outcome was shaped chiefly by species-specific attributes and context-dependent effects, such as variation among spatial locations (i.e. differences in remover presence, remover guild composition or differences in the intensity of remover activity due to variation in alternative food sources).

Our results showed that intense rodent activity was associated with vegetation cover in a similar way across regions, resulting in fairly predictable seed losses at a landscape level for both of them (cf. Fedriani et al., 2004). However, despite the spatially dependent post-dispersal seed removal activity described here, the generation of a spatially heterogeneous seed rain (Jordano and Schupp, 2000) translates pervasively to the subsequent stages of recruitment (García-Castaño, 2001), by determining hot-spots for successful seedling emergence that are non-randomly distributed over the microhabitat-patched landscapes studied here. Therefore, post-dispersal seed removal might be counterbalanced by other recruitment stages (i.e. seed production, seed dispersal, seed germination or seedling survival). On the one hand, in the case of life history specific adaptations, i.e. internal adjustments in the regeneration process, we would expect a similar overall recruitment among species. On the other hand, in cases where this is not found, i.e. species populations increase or go extinct, the observed pattern would be a consequence of the current ecological situation and local, landscape-level effects.

\section{Conclusions}

To summarize the results for the hypothesis tested, we can make the following concluding remarks.

We confirmed that the relative importance (i.e. variance explained) by the plant species and microhabitat effects (singly or interacting) should be greater than that explained by the other spatial effects. Moreover, once rodent presence was taken into account, the microhabitat effect disappeared as a single 
and as a plant-species-interacting effect (and although it appeared interacting with the region factor, its importance was lower than the plant species effect).

We found only partial evidence that the microhabitat effect was consistent across regions, without any interaction with this factor. This was true of seed removal without taking into account differences in rodent presence. However, a variation among regions (singly and interacting), related to differences in rodent activity, existed when including the rodent effect; this might be related to regional-specific environmental settings or to differences in the remover guilds.

Variation in seed removal rates should reflect the patterns in rodent presence at the different spatial levels considered. This pattern was confirmed at a microhabitat level (except for the lower than expected activity of rodents in the open microhabitat of Switzerland). Generally, the pattern was also confirmed at a more accurate level (i.e. location by location).

Although this study has produced clear results on patterns in post-dispersal seed removal, based on a comparison at different spatial levels, it is limited to a group of fleshy-fruited plant species in highland ecosystems of cool-temperate mountains. Therefore, extrapolations to other plant species and other ecosystems should be made carefully, especially with respect to potential effects on plant demography. Most important are effects of the remover guild, which can change markedly when ant and bird species are involved.

\section{Acknowledgements}

We greatly acknowledge the help by Kaspar Pflugshaupt and Marzio Fattorini during the fieldwork in Switzerland. Manuel Carrión suggested the type of seed dishes we used in the present study. Elisa Castaño, Juan García, Maㅡ Carmen García and Rosa Mํㅗ Zanca, among many others, helped in the intense manual fruit pulp removal process. Our work in Sierra de Cazorla was possible through the collaboration of Consejería de Medio Ambiente, Junta de Andalucía. The research for this paper was supported by the grants AP96-27318040, PB96-0857 and REN200300273 , from the Ministerio de Ciencia y Tecnología, to J.L.G.-C. and P.J. and by Research Grant 0-20 707-99 from the Forschungskommission ETH-Zurich to J.K.

\section{References}

Abramsky, Z. (1983) Experiments on seed predation by rodents and ants in the Israeli desert. Oecologia 57, 328-332.

Alcántara, J.M., Rey, P.J., Sánchez-Lafuente, A.M. and Valera, F. (2000) Early effects of rodent post-dispersal seed predation on the outcome of the plant-seed disperser interaction. Oikos 88, 362-370.

Benkman, C.W., Parchman, T.L., Favis, A. and Siepielski, A.M. (2003) Reciprocal selection causes a coevolutionary arms race between crossbills and lodgepole pine. American Naturalist 162, 182-194.

Blaney, C.S. and Kotanen, P.M. (2001) Post-dispersal losses to seed predators: an experimental comparison of native and exotic old field plants. Canadian Journal of Botany 79, 284-292.

Castien, E. and Gosálbez, J. (1996) Diet of Clethrionomys glareolus in the western Pyrenees (north Iberian Peninsula). Folia Zoologica 45, 137-144.

Castroviejo, S., Laínz, M., López González, G., Monserrat, P., Muñoz Garmendia, F., Paiva, J. and Villar, L. (1986, 1990) Flora iberica: Plantas vasculares de la Península Ibérica e Islas Baleares. Volumes I and II. Madrid, Real Jardín Botánico (CSIC).

Cromar, H.E., Murphy, S.D. and Swanton, C.J. (1999) Influence of tillage and crop residue on post-dispersal predation of weed seeds. Weed Science 47, 184-194.

Davidson, D.W. (1993) The effects of herbivory and granivory on terrestrial plant succession. Oikos 68, 23-35.

Díaz, I., Papic, C. and Armesto, J.J. (1999) An assessment of post-dispersal seed predation in temperate rain forest fragments in Chiloé Island, Chile. Oikos 87, 228-238.

Fedriani, J.M., Rey, P.J., Garrido, J.L., Guitián, J., Herrera, C.M., Medrano, M., Sánchez-Lafuente, A.M. and Cerdá, X. (2004) Geographical variation in the potential of mice to constrain an ant-seed dispersal mutualism. Oikos 105, 181-191.

García-Castaño, J.L. (2001) Consecuencias demográficas de la dispersión de semillas por aves y mamíferos frugívoros en la vegetación Mediterránea de montaña. PhD thesis, University of Seville.

Gryj, E.O. and Domínguez, C.A. (1996) Fruit removal and post-dispersal survivorship in the tropical dry forest shrub Erythroxylum havanense: ecological and evolutionary implications. Oecologia 108, 368-374.

Gurnell, J. and Little, J. (1992) The influence of trap residual odour on catching woodland rodents. Animal Behaviour 43, 623-632.

Hansson, L. (1985) The food of bank voles, woodmice and yellow-necked mice. Symposia of the Zoological Society of London 55, 141-168.

Hay, M.E. and Fuller, P.J. (1981) Seed escape from heteromyid rodents: the importance of microhabitat and seed preference. Ecology 62, 1395-1399.

Herrera, C.M. (1987) Vertebrate-dispersed plants of the Iberian Peninsula: a study of fruit characteristics. Ecological Monographs 57, 305-331.

Heske, E.J., Brown, J.H. and Guo, Q. (1993) Effects of kangaroo rat exclusion on vegetation structure and plant species diversity in the Chihuahuan Desert. Oecologia 95, 520-524.

Holl, K.D. and Lulow, M.E. (1997) Effects of species, habitat, and distance from edge on post-dispersal seed predation in a tropical rainforest. Biotropica 29, 459-468.

Hulme, P.E. (1997) Post-dispersal seed predation and the establishment of vertebrate dispersed plants in Mediterranean scrublands. Oecologia 111, 91-98. 
Hulme, P.E. (1998) Post-dispersal seed predation: consequences for plant demography and evolution. Perspectives in Plant Ecology, Evolution and Systematics 1, 32-46.

Hulme, P.E. (2002) Seed-eaters: seed dispersal, destruction and demography. pp. 257-273 in Levey, D.J.; Silva, W.R.; Galetti, M. (Eds) Seed dispersal and frugivory: Ecology, evolution and conservation. Wallingford, CABI Publishing.

Hulme, P.E. and Benkman, C.W. (2002) Granivory. pp. 132-154 in Herrera, C.M.; Pellmyr, O. (Eds) Plant-animal interactions. An evolutionary approach. Oxford, Blackwell Science.

Hulme, P.E. and Kollmann, J. (2005) Seed predator guilds, spatial variation in post-dispersal seed predation and potential effects on plant demography - a temperate perspective. pp. 9-30 in Forget, P.M; Lambert, J.E.; Hulme, P.E.; Vander Wall, S.B. (Eds) Seed fate: Predation, dispersal and seedling establishment. Wallingford, CABI Publishing.

Hyatt, L.A., Rosenberg, M.S., Howard, T.G., Bole, G., Fang, W., Anastasia, J., Brown, K., Grella, R., Hinman, K., Kurdziel, J.P. and Gurevitch, J. (2003) The distance dependence prediction of the Janzen-Connell hypothesis: a meta-analysis. Oikos 103, 590-602.

Jensen, S.P. (1993) Temporal changes in food preferences of wood mice (Apodemus sylvaticus L.). Oecologia 94, 76-82.

Jordano, P. (1995) Frugivore-mediated selection on fruit and seed size: birds and St. Lucie's cherry, Prunus mahaleb. Ecology 76, 2627-2639.

Jordano, P. and Schupp, E.W. (2000) Seed disperser effectiveness: the quantity component and patterns of seed rain for Prunus mahaleb. Ecological Monographs 70, 591-615.

Kelrick, M.I., Macmahon, J.A., Parmenter, R.R. and Sisson, D.V. (1986) Native seed preferences of shrub-steppe rodents, birds and ants: the relationship of seed attributes and seed use. Oecologia 68, 327-337.

Kirchhofer, W. (1982) Klimaatlas der Schweiz. Wabern, Bundesamt für Landestopographie.

Kollmann, J. (1995) Regeneration window for fleshy-fruited plants during scrub development on abandoned grassland. Écoscience 2, 213-222.

Kollmann, J. (2000) Dispersal of fleshy-fruited species: a matter of spatial scale? Perspectives in Plant Ecology, Evolution and Systematics 3, 29-51.

Kollmann, J. and Buschor, M. (2003) Edges effects on seed predation by rodents in deciduous forests of northern Switzerland. Plant Ecology 164, 249-261.

Kollmann, J. and Pflugshaupt, K. (2001) Flower and fruit characteristics in small and isolated populations of a fleshy-fruited shrub. Plant Biology 3, 62-71.

Kollmann, J. and Pflugshaupt, K. (2005) Population structure of a fleshy-fruited species at its range edge the case of Prunus mahaleb L. in northern Switzerland. Botanica Helvetica 115, 49-61.

Kollmann, J., Coomes, D.A. and White, S.M. (1998) Consistencies in post-dispersal seed predation of temperate fleshy-fruited species among seasons, years and sites. Functional Ecology 12, 683-690.

Maron, J.L. and Simms, E.L. (2001) Rodent-limited establishment of bush lupine: field experiments on the cumulative effect of granivory. Journal of Ecology 89, 578-588.
Moles, A.T. and Westoby, M. (2003) Latitude, seed predation and seed mass. Journal of Biogeography 30, 105-128.

Muñoz Garmendia, F. and Navarro, C. (1998) Flora iberica: Plantas vasculares de la Península Ibérica e Islas Baleares. Volume VI. Rosaceae. Madrid, Real Jardín Botánico (CSIC).

Myster, R.W. (2003) Effects of species, density, patch-type, and season on post-dispersal seed predation in a Puerto Rican pasture. Biotropica 35, 542-546.

Norconk, M.A., Grafton, B.W. and Conklin-Brittain, N.L. (1998) Seed dispersal by Neotropical seed predators. American Journal of Primatology 45, 103-126.

Pflugshaupt, K., Kollmann, J., Fischer, M. and Roy, B. (2002) Pollen quantity and quality affect fruit abortion in small populations of a rare fleshy-fruited shrub. Basic and Applied Ecology 3, 319-327.

Picó, F.X. and Retana, J. (2000) Temporal variation in the female components of reproductive success over the extended flowering season of a Mediterranean perennial herb. Oikos 89, 485-492.

Rey, P.J., Garrido, J.L., Alcántara, J.M., Ramírez, J.M., Aguilera, A., García, L., Manzaneda, A.J. and Fernández, R. (2002) Spatial variation in ant and rodent postdispersal predation of vertebrate-dispersed seeds. Functional Ecology 16, 773-781.

Schreiner, M., Bauer, E.-M. and Kollmann, J. (2000) Reducing predation of conifer seeds by clear-cutting Rubus fruticosus agg. in two montane forest stands. Forest Ecology and Management 126, 281-290.

Smith, T.J., Chan, H.T., McIvor, C.C. and Robblee, M.B. (1989) Comparisons of seed predation in tropical, tidal forests from three continents. Ecology 70, 146-151.

Sokal, R. and Rohlf, F.J. (1995) Biometry: The principles and practice of statistics in biological research (3rd edition). New York, W.H. Freeman.

Stoddart, D.M. and Smith, P.A. (1986) Recognition of odourinduced bias in the live-trapping of Apodemus sylvaticus. Oikos 46, 194-199.

Thompson, J.N. (1999) Specific hypotheses on the geographic mosaic of coevolution. American Naturalist 153, S1-S14.

Tutin, T.G., Heywood, V.H., Burges, N.A., Moore, D.M., Valentine, D.H., Walters, S.M. and Webb, D.A. (1968, 1976) Flora Europaea. Volumes 2 and 4. Cambridge, Cambridge University Press.

Valle, F., Gómez, F., Mota, F. and Díaz, C. (1989) Parque Natural de Cazorla, Segura y Las Villas. Guía botánicoecológica. Madrid, Editorial Rueda.

Wang, W., Ma, K.P. and Gao, X.M. (2000) Spatial and temporal patterns of Quercus liaotungensis acorn predation by vertebrates in Dongling Mountain, Northern China. Acta Botanica Sinica 42, 289-293.

Willson, M.F. and Whelan, C.J. (1990) Variation in postdispersal survival of vertebrate-dispersed seeds: effects of density, habitat, location, season, and species. Oikos 57, 191-198.

Received 11 July 2005

accepted after revision 28 March 2006

(c) CAB International 2006 